\title{
Association of the porcine $C 3$ gene with haemolytic complement activity in the pig
}

\author{
Supamit Mekchay, Siriluck Ponsuksili, \\ Karl Schellander, Klaus Wimmers* \\ Institute of Animal Breeding Science, University of Bonn, \\ Endenicher Allee 15, 53115 Bonn, Germany
}

(Accepted 4 February 2003)

\begin{abstract}
The complement component $C 3$ plays an essential role in the activated complement system, which is involved in phagocytosis, inflammation and immunoregulation to destroy infectious microorganisms. The $C 3$ molecule has more implications in the general defence mechanisms. In this study, the porcine $C 3$ cDNA sequences including $5^{\prime}$ - and $3^{\prime}$ - flanking regions were determined and the polymorphisms in this gene were identified to carry out an association analysis between $C 3$ and complement activity traits. Porcine $C 3$ gene has high homology with human C3. Five single nucleotide polymorphisms (SNPs) and one microsatellite were detected in the porcine $C 3$ gene. Haemolytic complement activity of alternative and classical pathways $(\mathrm{ACH}, \mathrm{CCP})$ was measured in 416 F2 animals of a crossbred of Duroc $\times$ Berlin Miniature Pig, which were immunized with Mycoplasma, Aujeszky and PRRS vaccines. C3 markers were found to be significantly associated $(P<0.05)$ with both ACP and CCP. Animals with the more frequent haplotype present in Duroc and other commercial breeds exhibit higher ACP and CCP levels than the animals with haplotype specific to some Berlin Miniature Pigs. The association of $C 3$ with complement activity reinforces the importance of $C 3$ as a candidate gene for natural resistance to microorganisms.
\end{abstract}

porcine $C 3$ gene / natural resistance / haemolytic complement activity / association / pig

\section{INTRODUCTION}

The complement cascade defines an important link between the innate and the specific immune system [13]. The complement component $C 3$ is the key molecule of the three pathways of complement activation (alternative, classical and lectin pathways), which are involved in phagocytosis, inflammation and immunoregulation processes to destroy infectious microorganism [19].

\footnotetext{
* Correspondence and reprints
}

E-mail: kwim@itz.uni-bonn.de 
C3 deficiency in hosts causes increasing susceptibility to bacterial or viral infections $[1,4,13,22]$. $C 3$ has more implication in general defence mechanisms. We have previously found polymorphic sites within the porcine $C 3$ which were used for genetic mapping of the locus [25]. The present study was carried out to investigate the porcine $C 3$ gene as a candidate gene for complement activity traits. Therefore, the full length cDNA sequence of the porcine $C 3$ as well as $5^{\prime}$ - and $3^{\prime}$ - flanking regions were obtained, screened for additional polymorphisms in this gene and, finally, association analysis was conducted between $C 3$ markers and complement activity traits.

\section{MATERIALS AND METHODS}

\subsection{Animals}

Sequence information of the porcine $C 3$ gene was identified in a DUMI F2animal of a reciprocal cross of Duroc $\times$ Berlin Miniature Pig [9]. Screening for polymorphisms in the porcine $C 3$ gene was performed in Duroc $(\mathrm{n}=6)$, German Landrace $(n=28)$, Pietrain $(n=23)$, DUMI F2 $(n=902)$ and Thai native $(\mathrm{n}=32)$ pigs. For association study, haemolytic complement activity was recorded in 416 animals of the DUMI-F2 resource population.

\section{2. cDNA sequence and $5^{\prime}$ and $3^{\prime}$ flanking regions of the porcine $C 3$ gene}

Total RNA was extracted from pig liver using TRIzol ${ }^{\mathrm{TM}}$ Reagent (Life Technologies, Karlsruhe, Germany). Full length porcine $C 3$ cDNA sequence was determined by the SMART ${ }^{\mathrm{TM}}$ RACE cDNA Amplification Kit (Clontech, Heidelberg, Germany). RACE primers and gene specific primers were designed based on partial porcine $C 3$ sequence information (GenBank accession number AF110278, F14640) (Fig. 1):

\footnotetext{
RACE: $5^{\prime}$-ctaatacgactcactatagggcaagcagtggtatcaacgcagagt- $3^{\prime}$

C3-A2: $\quad 5^{\prime}$-ccttctccacgacatcccagatcctacg- $3^{\prime}$

C3-B1: $\quad 5^{\prime}$-ccaccaagaccatgaatgtg-3'

C3-B2: $\quad 5^{\prime}$-tagagcttctggecaggttc-3'

C3-C1: $\quad 5^{\prime}$-ggtggtgaccatgtaccacg-3'.
}

The $5^{\prime}$ and $3^{\prime}$ flanking regions of porcine $C 3$ gene were isolated from a genomic DNA library, which was constructed using Lambda DASH II $^{\circledR}$ (Stratagene, Amsterdam, Netherlands). Two positive clones of $5^{\prime}$ and $3^{\prime}$ flanking region were amplified with primers specific to porcine $C 3$ ( $5^{\prime}$-flanking region $5^{\prime}$ tgtgccccttctctgatttg-3', $3^{\prime}$-flanking region $5^{\prime}$-gctccgatgaagtgcaggt-3') and T3/T7 


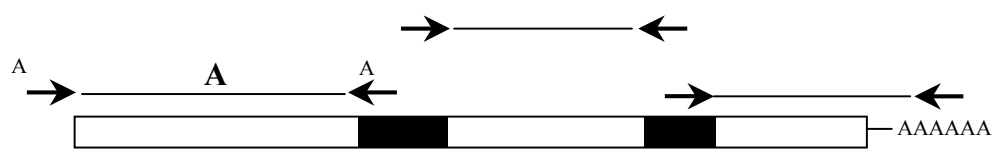

Figure 1. Amplification of the full-length porcine $C 3$ gene. Three PCR fragments (A, B and C) were amplified with primers based on available porcine $C 3$ sequence in GenBank, a 580-bp partial cDNA fragment (shaded area 1) (accession No. AF110278) and a 462-bp EST of porcine C3 (shaded area 2) (accession No. F14640).

standard primers. All the PCR fragments were ligated in $\mathrm{pGEM}^{\circledR}$-T vector (Promega, Mannheim, Germany) and sequenced using the SequiTherm Excel cycle sequencing Kit (Epicentre Technologies, Biozym, Hessisch Oldendrof, Germany) and a LI-COR 4200 automated sequencer (LI-COR Biosciences, Bad Homburg, Germany).

\subsection{Polymorphism screening and marker genotyping}

To identify polymorphisms in the porcine $C 3$ gene, oligonucleotide primers were designed revealing 17 overlapping PCR fragments (Tab. I). They were amplified from individual liver cDNA and genomic DNA of six pig breeds. PCR was performed in a $25 \mu \mathrm{L}$ reaction volume containing $50 \mathrm{ng}$ of liver cDNA, $0.2 \mu \mathrm{M}$ of each primers, $50 \mu \mathrm{M}$ each dNTPs, $0.5 \mathrm{U}$ of $P f u$ polymerase (Promega) in $1 \times P f u$-PCR buffer. PCR cycling program was $94^{\circ} \mathrm{C}$ for $3 \mathrm{~min}$, followed by 35 cycles of $94{ }^{\circ} \mathrm{C}$ for $30 \mathrm{~s}, 52-60^{\circ} \mathrm{C}$ (Tab. I) for $30 \mathrm{~s}, 72^{\circ} \mathrm{C}$ for $1 \mathrm{~min}$ and final extension at $72^{\circ} \mathrm{C}$ for $5 \mathrm{~min}$. PCR products were gel purified, cloned and sequenced. The nucleotide sequences of each animal were compared to find out polymorphisms in the porcine $C 3$ gene.

To genotype each polymorphic site in the porcine $C 3$ gene, PCR-RFLP, allele specific PCR, SSCP and microsatellite analysis were performed. Oligonucleotide primers (Tab. II) were used to amplify PCR fragments from genomic DNA. PCR reactions were carried out in $20 \mu \mathrm{L}$ volume using Taq polymerase (Promega). Amplified PCR fragments with primer C3-I (Tab. II) were mixed with $1: 10$ with loading buffer $(95 \%$ formamide, $10 \mathrm{mM} \mathrm{NaOH}$, $0.25 \%$ bromophenol blue, $0.25 \%$ xylenecyanol), denatured at $95^{\circ} \mathrm{C}$ for $5 \mathrm{~min}$, then cooled on ice immediately and separated on $12 \%$ polyacryamide gel (49:1 acrylamide/bis-arylamide) at room temperature with a constant $12 \mathrm{~W}$ for $6 \mathrm{~h}$ in $0.5 \times$ TBE. The SSCP-bands were stained by silver staining procedure. Amplicon C3-II was digested with restriction enzyme TaqI (Promega). The digested PCR fragments were analysed on $2 \%$ agarose gels. Genotyping the SNPs within amplicons C3-III and C3-IV was done as described previously [25]. Fragments with length polymorphism were amplified with primer C3-V (Tab. II) and were identified on $6 \%$ SequiGel ${ }^{\circledR} \mathrm{XR}$-denaturating polyacrylamide gels 
Table I. Primer sequences used for screening polymorphisms in the porcine $C 3$ gene.

\begin{tabular}{|c|c|c|c|c|c|}
\hline Name & $\begin{array}{l}\text { Forward primer sequence } \\
\qquad\left(5^{\prime} \text { to } 3^{\prime}\right)\end{array}$ & $\begin{array}{l}\text { Reverse primer sequence } \\
\left(5^{\prime} \text { to } 3^{\prime}\right)\end{array}$ & $\begin{array}{l}\text { Annealing } \\
\text { temp. }\left({ }^{\circ} \mathrm{C}\right)\end{array}$ & $\begin{array}{c}\text { cDNA } \\
\text { (bp) }\end{array}$ & $\begin{array}{c}\text { Genomic- } \\
\text { DNA } \\
\text { (bp) }\end{array}$ \\
\hline $\mathrm{C} 3-5^{\prime}$ & GCATCGACTTGAATTCACAG & CCATGATGGAGGGACGGTG & 55 & - & 477 \\
\hline C3-01 & TCCTTTCCCTCTGTCCCTTT & GGGAGTCCCGTTTGATGTC & 58 & 577 & - \\
\hline C3-02 & TGAGACACCTGAAGGCATTG & GCTGTTCCATCCACACTCTC & 58 & 306 & $\sim 700$ \\
\hline C3-03 & TCAACATCATTGCCAGGTTC & GGGTCTTGGTGAAGTGGATC & 59 & 324 & - \\
\hline C3-04 & CATCGTGACCTCCCCCTATC & GTGCGCAGGTGGAAGTTAAC & 59 & 393 & $\sim 1000$ \\
\hline C3-05 & TCAAGCCAGGGGAGAATCTC & TCTCCAGGGTCATCTGTTGC & 56 & 360 & $\sim 1500$ \\
\hline C3-06 & GAAGCAAGACAAGCAGCATC & TGTCCATCCTTTTCTCCATG & 56 & 338 & $\sim 900$ \\
\hline C3-07 & GTGCAGCTCATGGAGAAAAG & ATTCATGGTCTTGGTGGAG & 56 & 360 & - \\
\hline C3-08 & CTCCACCAAGACCATGAAT & TCTTCAAGGGCACAATG & 54 & 356 & - \\
\hline C3-09 & CATTGTGCCCTTGAAGA & GTGCTGTCCAGGTAGTGC & 55 & 396 & - \\
\hline C3-10 & CAGTCATCGCTGTGCACTA & GTTCTTGAAGCCACCAATC & 55 & 343 & - \\
\hline C3-11 & GATTGGTGGCTTCAAGAAC & CTACCAGCAGAGCCAAG & 52 & 341 & - \\
\hline C3-12 & CTTGGCTCTGCTGGTAG & CGTGGTACATGGTCAC & 52 & 338 & $\sim 1000$ \\
\hline C3-13 & GTGACCATGTACCACG & CCTCCAGGGTGTGTGAGAC & 52 & 337 & $\sim 1300$ \\
\hline C3-14 & GATCTCACACACCCTGGAGG & CACTTCATCGGAGCCTGATT & 55 & 379 & - \\
\hline C3-15 & AATCAGGCTCCGATGAAGTG & GGCAACCAAAGACGACCAT & 56 & 270 & - \\
\hline $\mathrm{C} 3-3^{\prime}$ & TGGCCAACTTCTCTGAGAAC & TGCAGGCAGATACAGTTGAG & 60 & - & 530 \\
\hline
\end{tabular}


Table II. Nucleotide sequence primers for genotyping the polymorphisms in the porcine $C 3$ gene.

\begin{tabular}{llcc}
\hline Amplicon & \multicolumn{1}{c}{ Primer $\left(5^{\prime}\right.$ to $\left.3^{\prime}\right)$} & Size (bp) & $\begin{array}{c}\text { Annealing } \\
\text { temp. }\left({ }^{\circ} \mathrm{C}\right)\end{array}$ \\
\hline C3-I & F: GCATCGACTTGAATCACAG & 477 & 55 \\
& R: CCATGATGGAGGGACGGTG & & \\
C3-II & F: CACCCTGATTGCTGCCAATG & 383 & 60 \\
& R: TACCTCAACTTACTGCGGTC & & \\
C3-III & F: TGAGAATGTGGATGGACCAG & 384 & 60 \\
& R: GGACTTGAATGCCCAAGATC & & \\
C3-IV & F1: AAGGATCTGAACCTGGATGTA & 454 & 64 \\
& F2: GGATCTGAACCTGGATGTG & 452 & \\
& R: ACCCCGCTAATCTGTGATGC & & \\
C3-V & F: TGGCCAACTTCTCTGAGAAC & 204,207 & 60 \\
& R: TAGGATGAACCTGAGCTGTG & 211 & \\
\hline
\end{tabular}

(Biozym Diagnostik GmbH) by the LI-COR 4200 automated sequencer (LICOR Biosciences). The fragment size of alleles was analysed by One-Dscan software (Scanalytics, MWG Biotech).

\subsection{Haemolytic complement activity phenotypes}

Total haemolytic complement activities were determined in 416 F2-animals of the DUMI-resource population produced from $11 \mathrm{~F} 1$ sows ( 2 full-sib groups) mated with 3 F1 boars. The animals were reared in the Frankenforst research farm of the University of Bonn. They were immunized with Mycoplasma, Aujeszky and PRSS vaccines at 6,14 and 16 weeks of age, respectively. Blood samples were taken immediately before vaccination and on 4 and/or 10 days after vaccination (Fig. 2). Total haemolytic activity of the alternative (ACP) and classical complement pathway (CCP) was determined by a method modified from Liu and Young [15]. Non sensitised rabbit erythrocytes and sensitised sheep erythrocytes were used as target cells, for ACP and CCP respectively. The haemolytic complement activity was expressed as the titre that lysed $50 \%$ of erythrocytes (CH50 unit $\cdot \mathrm{mL}^{-1}$ ).

\subsection{Association analysis between $C 3$ and complement activity traits}

Association between $C 3$ markers and haemolytic complement activity traits was analysed using the REPEATED statement of the SAS ${ }^{\circledR}$ PROC MIXED procedure [14]. The statistical model included $C 3$ genotype, time of blood 


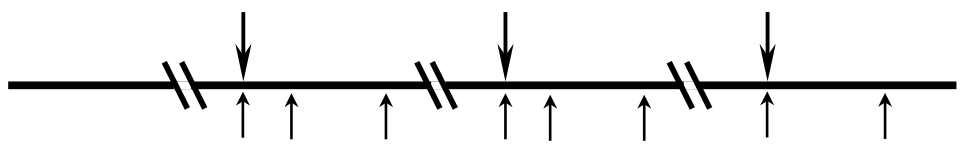

Figure 2. Vaccination programme and time of blood sampling in the DUMI-F2 resource population.

sampling, sire, and interaction of $C 3$ genotype and time of blood sampling as fixed effects, and dam nested within sire as random effect. A heterogeneous compound-symmetry (CSH) covariance structure was included in the statistical model to analyse fixed effects because it gave the best fit when compared to other covariance structures.

\section{RESULTS}

\subsection{Sequence analysis of the porcine $C 3$ gene}

The complete porcine $C 3$ cDNA sequence (accession No. AF154933) was determined. The $5127 \mathrm{bp}$ cDNA contains an open reading frame coding for 1661 amino acids, including a 22-amino acids signal peptide, 643 amino acids $\beta$-chain, a 4 amino acids linker and 992 amino acids $\alpha$-chain. The ORF of porcine $C 3$ shows 80,78 and $77 \%$ homology with human, rat and mouse $C 3$ nucleotide sequence, respectively $[6,7,17]$. The 63 bp 5'-UTR is a pyrimidine rich region (approximately $80 \%$ pyrimidines). A 56 bp of 3'-UTR was sequenced and a polyadenylation signal (AATAAA) was found at position 5074 to 5079 of cDNA sequence (AF154933). The sequence information of the $5^{\prime}$-flanking region (Fig. 3a) contained several features of promoter region. The putative TATA-box (GATAAA) sequence was located at $-29 \mathrm{bp}$ of the first nucleotide $C 3$ sequence (AF154933) and various putative enhancer/transcription factor binding sequences were also found (Tab. III). Comparison of the porcine $5^{\prime}$-flanking sequence with the promoter region of human $C 3$ sequence (X62904) [10] revealed 74\% sequence identity. However, the 3 '-flanking region (Fig. $3 \mathrm{~b}$ ) of porcine $C 3$ had low homology with human C3 sequence (M63422) [21].

\subsection{Polymorphism and allelic frequency of the porcine $C 3$ gene}

Six polymorphic sites were found in the porcine $C 3$ gene including five SNPs and one microsatellite (Fig. 4a). Two SNPs were found in the 5'-flanking 
-487 GACTCTTGCT GCCAGCATCG ACTTGAATTC ACAGGAAGGG TTTGGTTAAT -437 AAGTGCATGG CCAAAAGTGG ACTGAGAGCC AGGTGCAGAT ATCGGGGAAG -387 GGGGGCAGGC ACTATCTGGG GAAGAGAGAA TAATTTTCCT CCACTACAAA -337 GTGGGTATAG CAGGGACAGG TCCCCATTCA CCAGCCAGCC TTGACCATGA -287 GAGAGGCCAG GGCAGGAGGC TGTTGTATTC TTGTTGCAGG AGGACGTGCC -237 CTTAGGTTAT TTTCCCCAGG ACTGTGATGG CCACACAGAT TGAAAAACTT -187 TGGAAATGAC ATTGAGAAAT CTGGGGCAGC CCCAGGGAGG GGGGAGGCCA $-137$ CAGGGAGTGG A GGCAGCCT CC AGGGCTGGGC TCCCTCTGTC CCAGCAGCCT TGAAGAGGGG GAAAAGCAGC TGCCAE ............ Gingin

CTGCTCACTT CCCCCCCCAC CCCCGTCCTT CCTTTGTCCC TCCACCGTCC

CTCCATCATG

........

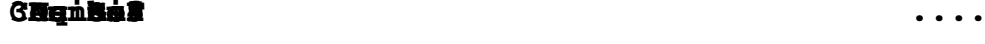

TGATGCCACT CCCCCACAGT CTACCCR A GCTCCAGT TATCTTTCAC

ATTTCCCCCC ACATCTGAAG GTCTTTTTTT

GAGAGGGGAA AAGAGGCAGC TGTGATCCCG TTTTTTTTTT GAAGGTCTTT CAGGTTCATC CTACTGAAAC TCCACCTGCT CCACTGCCTC ACCCACAGCT

151 CAGTTCACCC GGCTTCCTGG CCTCAAGTGC CCTAGCGGGC AGTACATCTG CAGCTTCCCC TG TCCCACTTCA TCCCCTCCAG

251

301 ATCCTTACCC AAA AAATTCTCAT TTACATTCTC ATGTACCTGC CTTACCTGCA

351 CTCACTGTCC CII CTTCACCTGA GCTTTCACCA GCATCTCCC CTGCACCCCC ATTTCATCCT CACCTGAGCT TTTCCCAATA GTCTCAGCTG AATCTTCACC CTCTCTCACC TGCACACTCA ACTGTATCTG CCTGCATTTT CTGCATCTTC ССTGCTTCCC CСАССTACAT СTTAATCTGT AAACTTAACT GTATCTCTAC CAACATTCTT TCCTTTATTC TCACCTTGTC TTTCTACCTG TATCCTTACC TGTATTTTCT CTGCATCCTC CTCAGGGTGA GGAACTGCAT CTTTGCCTAC ATCCCTCTCT AGTCTCTTTC CTGTGTTCTC ACCAGCATCC TTAGCTACAT TCTCACCTAC ATCTTCCCCT GCATCTTTTT TTTGCTTTTT TTTTTTTTGC TTTTTTTTTG CTTTTTAGGG CCACACCCAC GGCATATGGA GGTTCCCAAG CTAGGGGGCA AATTGGAGCT GCAGCTGCCA GCCTCACCAC AGCCACATCA ATGCAGGATC CGAATTCTTC GCCCTATAGT GAGT

Figure 3. Sequence of the $5^{\prime}$-flanking region upstream from ATG start codon (a) and of the $3^{\prime}$-flanking region downstream from TGA codon (b) of the porcine $C 3$ gene (accession No. F154933). The 5'-UTR is indicated in italics and the putative transcription start site is indicated in italics, bold and underlined. A putative TATA box and polyadenylation signal are indicated in bold and underlined in the $5^{\prime}$ - and 3 '-flanking regions, respectively.

region at position $-384(\mathrm{G}>\mathrm{A})$ and $-44(\mathrm{C}>\mathrm{T})$ nucleotide $(\mathrm{nt})$ upstream ATG start codon. The other three SNPs were located in the coding region at $1905(\mathrm{C}>\mathrm{A}), 3882(\mathrm{G}>\mathrm{A})$ and the $\mathrm{nt} 204(\mathrm{~T}>\mathrm{C})$ of the intron 13. A microsatellite with $(\mathrm{T})_{14}-21$-repeat units was found in the $3^{\prime}$-flanking region of $C 3$ and was located at 71 bp downstream from the TGA stop codon.

The two SNPs of $5^{\prime}$-flanking region were genotyped by SSCP analysis (Fig. 4b). Taq I-RFLP was used to detect the variation of the nt 204 in the intron 13 of C3-cDNA sequence (amplicon C3-II) and showed either undigested PCR product (384 bp, allele T), and/or digested product (285 bp and 143 bp, allele C) (Fig. 4c). Similarly, restriction enzyme Hsp92 I was used to test polymorphism at position 1502 (amplicon C3-III) and revealed either 
Table III. Position of transcription factor binding sites in the $5^{\prime}$-flanking region of the porcine $C 3$ gene.

\begin{tabular}{llccc}
\hline Factor & Consensus sequence & Position & Homology $(\%)$ & Ref. \\
\hline Enhancer core & GGGGAAAA & -110 to -103 & 88 & {$[8]$} \\
\hline C/EBP & TTGAGAAAT & -176 to -168 & 100 & {$[23]$} \\
\hline IL-6-RE & AGGGGGA & -112 to -106 & 86 & {$[21]$} \\
& TCTGGGG & -168 to -162 & 100 & {$[21]$} \\
& TGAGAAA & -175 to -169 & 100 & {$[21]$} \\
& TGAAAAA & -197 to -191 & 100 & {$[21]$} \\
& TGAGAGA & -290 to -284 & 100 & {$[21]$} \\
& TGGGGAA & -371 to -365 & 100 & {$[21]$} \\
\hline IL-6 RE rev & TTCCCCA & -220 to -226 & 100 & {$[8]$} \\
& TCCTCCA & -351 to -345 & 100 & {$[8]$} \\
\hline IFN $\gamma$ RE & GAAAAACTTTGGAAA & -196 to -192 & 87 & {$[8]$} \\
\hline AP-2 & CCCTTAGG & -132 to -139 & 88 & {$[18]$} \\
\hline LF-A1 & TGGCCA & -210 to -205 & 83 & {$[8]$} \\
& TGGACT & -420 to -415 & 83 & {$[8]$} \\
\hline LF-B1/HNF-1 & GTTAAT & -443 to -438 & 100 & {$[8]$} \\
& GTTATT & -232 to -227 & 83 & {$[8]$} \\
\hline Estrogen RE & TGTCCCTTTGTCC & -31 to -19 & 85 & {$[21]$} \\
\hline
\end{tabular}

digested PCR product (237 bp and $146 \mathrm{bp}$, allele C) and/or $383 \mathrm{bp}$ (allele A) of undigested product (Fig. 4d). The SNP located at 3882 was genotyped by allele specific PCR technique with two different primer sets (Fig. 4e). Microsatellite analysis in the $3^{\prime}$-flanking region of porcine $C 3$ revealed three alleles of 211, 207 and $204 \mathrm{bp}$ (amplicon $\mathrm{C} 3-\mathrm{V}$ ), and these alleles corresponded to $(\mathrm{T})_{21^{-}}$,

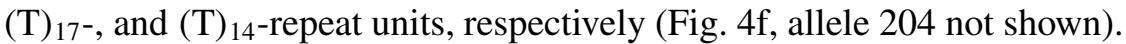

Five of these polymorphic sites (at positions -44, 204 of intron 13, 1509, 3882 and +71) were segregating in the DUMI F2-resource population, and these alleles were coming from some Berlin Miniature Pig of the grandparent generation. All six polymorphic sites were segregating only in Thai native pigs, but no polymorphism was found among the 86 Duroc, German Landrace, Large White and Pietrain pigs. Allelic frequencies of the polymorphic sites in porcine $C 3$ gene among pig breeds are given in Table IV.

\subsection{Association analysis}

Means and standard deviation of the haemolytic complement activity of alternative and classical pathways were estimated (Tab. V). Only 3 SNPs 


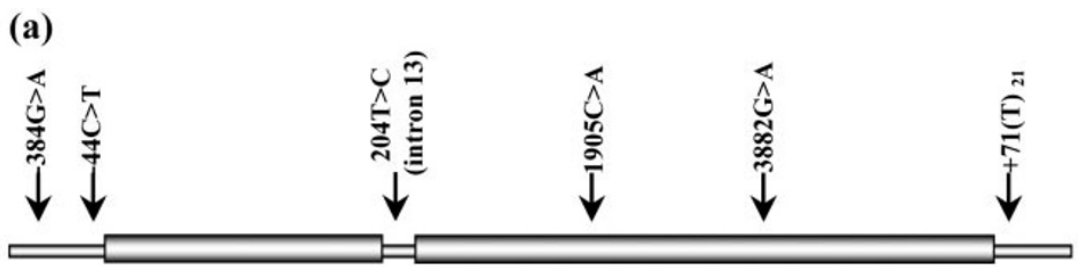

(b)

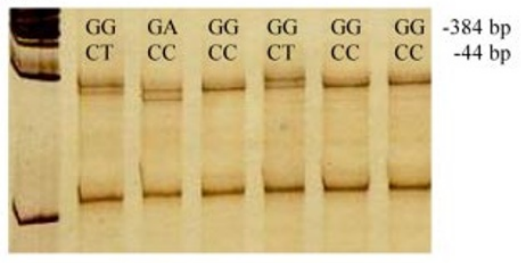

(c)

(d)
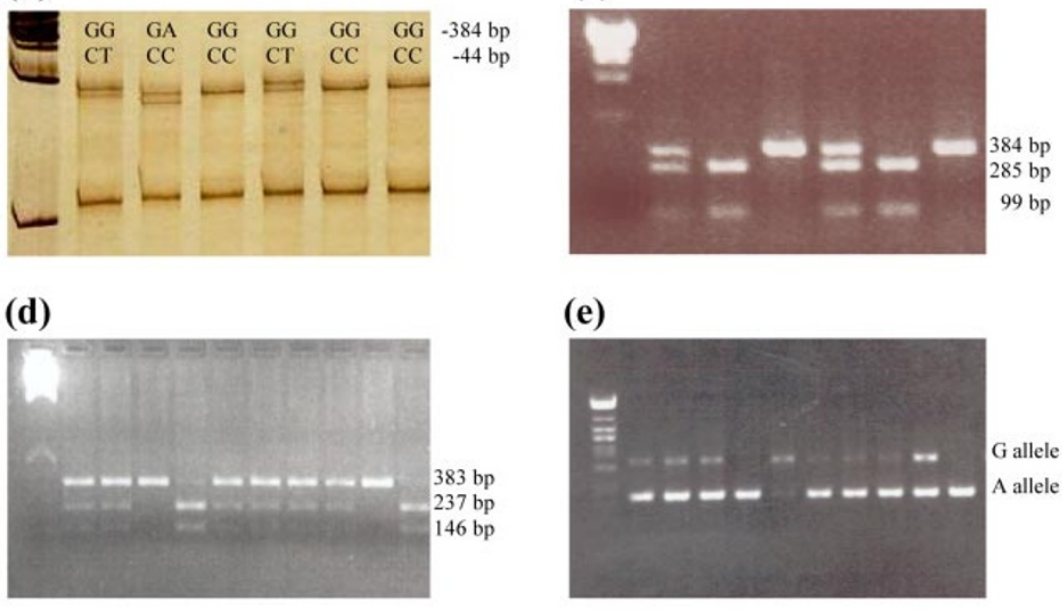

(e)

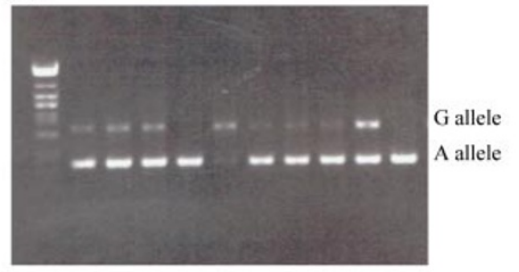

(f)

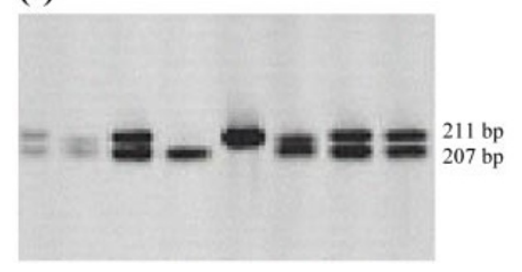

Figure 4. Polymorphism in the porcine $C 3$ gene including the $5^{\prime}$ - and $3^{\prime}$-flanking regions (a); SSCP analysis at positions -384 and -44 bp in the $5^{\prime}$-flanking region (b); TaqI- PCR-RFLP test at position 204 in intron 13 (c); Hsp92 I-PCR-RFLP test at position 1905 (d); allele specific PCR test at position 3882 (e); and SSLP analysis at position +71 bp in the $3^{\prime}$-flanking region $(\mathbf{f})$.

and one microsatellite (nt 204 of intron 13, 1905, 3882, +71) were genotyped. These four alleles were segregating with two haplotype patterns that can be described [2] as follows: allele $C 3 * 1$, [IVS13+204T; 1905C; $3882 \mathrm{G} ;$ c. $5038+71(\mathrm{~T})_{21}$ ] and allele $C 3 * 2$, [IVS13+204C; 1905A; 3882A; c.5038+71(T $\left.)_{17}\right]$. The numbers of pigs for each genotype class were 290,109 and 17 for $C 3 * 1 / C 3 * 1, C 3 * 1 / C 3 * 2$ and $C 3 * 2 / C 3 * 2$ genotypes respectively. Subsequently, the genotype $C 3 * 2 / C 3 * 2$ was excluded from the analysis because of its low frequency and unequal distribution over parities and litters. 
Table IV. Allele frequencies at the porcine $C 3$ gene in six genetic groups of pigs.

\begin{tabular}{lccccccc}
\hline Position & Allele & \multicolumn{7}{c}{ Frequency } \\
\cline { 3 - 8 } & & $\begin{array}{c}\text { F2- } \\
\text { DUMI }\end{array}$ & Duroc & $\begin{array}{c}\text { German } \\
\text { Landrace }\end{array}$ & $\begin{array}{c}\text { Large } \\
\text { White }\end{array}$ & Pietrain & $\begin{array}{c}\text { Thai } \\
\text { native pig }\end{array}$ \\
\hline-384 & $\mathrm{G}$ & 1.00 & 1.00 & 1.00 & 1.00 & 1.00 & 0.99 \\
-44 & $\mathrm{G}$ & 0.99 & 1.00 & 1.00 & 1.00 & 1.00 & 0.97 \\
204 (intron 13) & $\mathrm{T}$ & 0.75 & 1.00 & 1.00 & 1.00 & 1.00 & 0.82 \\
1905 & $\mathrm{C}$ & 0.74 & 1.00 & 1.00 & 1.00 & 1.00 & 0.70 \\
3882 & $\mathrm{G}$ & 0.74 & 1.00 & 1.00 & 1.00 & 1.00 & 0.82 \\
$+71(\mathrm{~T})_{21}$ & $\mathrm{~T}_{21}$ & 0.76 & 1.00 & 1.00 & 1.00 & 0.00 & 0.71 \\
$+71(\mathrm{~T})_{17}$ & $\mathrm{~T}_{17}$ & 0.24 & 0.00 & 0.00 & 0.00 & 0.00 & 0.12 \\
$+71(\mathrm{~T})_{14}$ & $\mathrm{~T}_{14}$ & 0.00 & 0.00 & 0.00 & 0.00 & 0.00 & 0.17 \\
\hline
\end{tabular}

Table V. Haemolytic complement activities (mean \pm SD) of alternative and classical pathways in DUMI resource population.

\begin{tabular}{lcc}
\hline & \multicolumn{2}{c}{ Haemolytic complement activity $\left(\right.$ Unit $\left.\cdot \mathrm{mL}^{-1}\right)$} \\
\cline { 2 - 3 } Blood sampling & ACH50 & CCH50 \\
\hline Time-1 & $53.64 \pm 28.31$ & $40.70 \pm 23.13$ \\
Time-2 & $53.22 \pm 28.43$ & $48.23 \pm 28.81$ \\
Time-3 & $55.05 \pm 24.86$ & $47.97 \pm 29.19$ \\
Time-4 & $56.86 \pm 30.13$ & $59.08 \pm 36.46$ \\
Time-5 & $62.31 \pm 32.08$ & $64.91 \pm 35.71$ \\
Time-6 & $68.46 \pm 47.63$ & $59.79 \pm 39.10$ \\
Time-7 & $69.75 \pm 41.70$ & $62.53 \pm 35.58$ \\
Time-8 & $69.71 \pm 37.42$ & $60.99 \pm 40.89$ \\
\hline
\end{tabular}

Table VI. Significance in analysis of variance of alternative (ACH50) and classical (CCH50) complement activity traits.

\begin{tabular}{lcccc}
\hline & \multicolumn{4}{c}{ Test of fixed effects $(P$ value $)$} \\
\cline { 2 - 5 } Traits & $C 3$ marker & Time & $C 3 \times$ time & Sire \\
\hline ACH50 & 0.0255 & $<0.0001$ & $<0.0001$ & $<0.0001$ \\
CCH50 & 0.0286 & $<0.0001$ & 0.0014 & 0.0151 \\
\hline
\end{tabular}

Analysis of variance revealed that hemolytic complement activity of both alternative and classical pathways was significantly affected $(P<0.05)$ by $C 3$ marker, time of blood sampling and their interaction, and by sire effect (Tab. VI). The profiles of the haemolytic complement activities between the different $C 3$ 

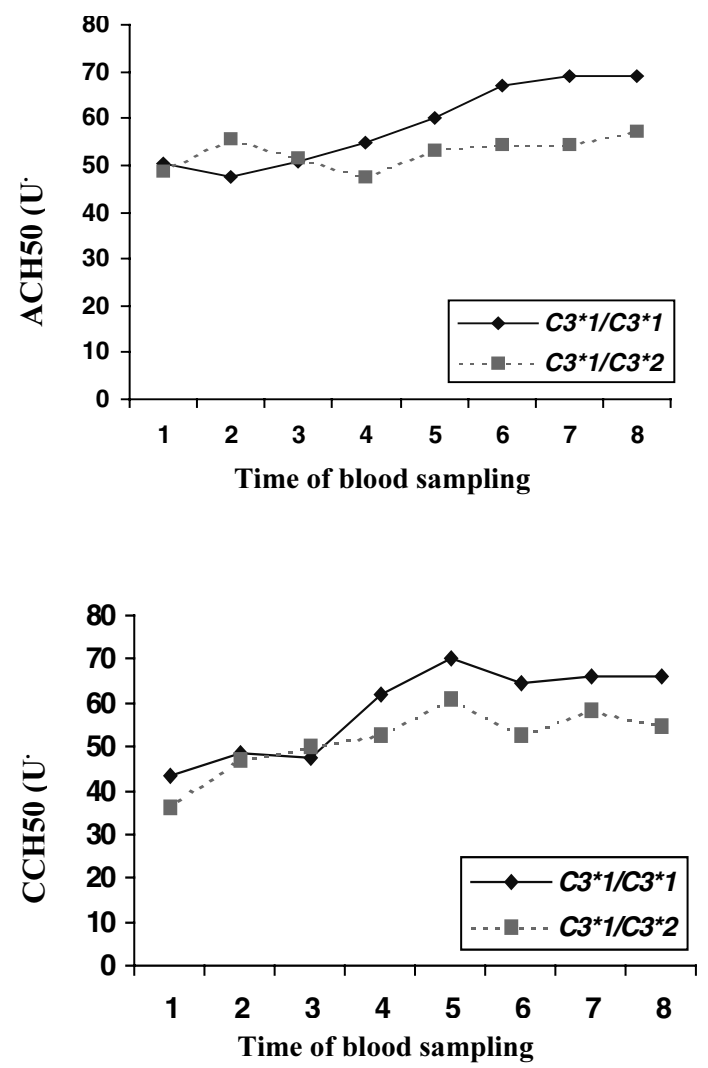

Figure 5. Haemolytic complement activity profiles of alternative (a) and classical (b) pathways for pigs with $C 3 * 1 / C 3 * 1$ and $C 3 * 1 / C 3 * 2$ haplotypes.

genotypes were not parallel over time (Fig. 5). Complement activities in the alternative and classical pathway were 5.8 and 6.9 units $\cdot \mathrm{mL}^{-1}$ higher for animals homozygous for the $C 3 * 1$ allele than for $C 3 * 1 / C 3 * 2$ animals.

\section{DISCUSSION}

Activated complement system plays an important role in killing and neutralization of microorganisms, and $C 3$ is a key molecule of this system. Therefore, C3 can be regarded as a candidate gene for complement activities. The $5.1 \mathrm{~kb}$ sequence of full-length porcine $C 3$ gene has a 4983-bp ORF which coded for $\alpha$ - and $\beta$-chain of $C 3$ protein. The porcine $C 3$ is a conserved gene and has high homology with the other mammalian species $C 3$ gene. Indeed, the putative promoter region contains one TATA-box and several cis-regulating 
elements similar to that of the human $C 3$ promoter [8,21]. The variation of haemolytic complement activities before and after vaccination within the F2-DUMI resource population was found to be associated with $C 3$ markers. Although these $C 3$ markers were silent at the amino acids level, another nucleotide exchange in the $5^{\prime}$-flanking promoter region of the $C 3$ gene and in linkage disequilibrium with these $C 3$ variants might be responsible for its function. Animals with the more frequent $C 3 * 1 / C 3 * 1$ haplotype, present in Duroc and other commercial breeds, exhibited higher complement reactivity than those carrying the allele $C 3 * 2$ coming from Berlin Miniature Pigs.

Genetic variation in $C 3$ affecting the complement activity has been observed in human [3], rabbit [11], and mouse [5]. These reports indicated that the genetic defect of $C 3$ gene caused low (or lack of) haemolytic complement activity and increased susceptibility to microorganisms. Phenotypic variation of haemolytic complement activity in pigs has been associated with effects due to vaccination, genomic variation at the swine leukocytes antigen locus (SLA) [16,20], breed [12], age as well as sire or/and dam [16,24].

Although the complement is a complex system and is controlled by many genes, the present work showed there was an association of $C 3$ and haemolytic complement activity - a defence mechanism active against many pathogenic agents - which reinforces the importance of $C 3$ as a candidate gene for natural resistance to microorganisms.

\section{ACKNOWLEDGEMENTS}

We wish to express our great appreciation to Prof. Dr. S. Rattanaronchart, Department of Animal Science, Faculty of Agriculture, Chiang Mai University, Thailand, for providing us with the blood samples. We would also like to thank the German research Council (DFG), and the German Academic Exchange Service (DAAD) for financial aid.

\section{REFERENCES}

[1] Ameratunga R., Winkelstein J.A., Brody L., Binns M., Cork L.C., Colombani P., Valle D., Molecular analysis of the third component of canine complement (C3) and identification of the mutation responsible for hereditary canine $C 3$ deficiency, J. Immunol. 160 (1998) 2824-2830.

[2] Antonarakis S.E., Nomenclature Working Group, Recommendations for a nomenclature system for human gene mutations, Hum. Mutat. 11 (1998) 1-3.

[3] Botto M., Fong K.Y., So A.K., Rudge A., Walport M.J., Molecular basis of hereditary $C 3$ deficiency, J. Clin. Invest. 86 (1990) 1158-1163.

[4] Botto M., Fong K.Y., So A.K., Barlow R., Routier R., Morley B.J., Walport M.J., Homozygous hereditary $C 3$ deficiency due to a partial gene deletion, Proc. Natl. Acad. Sci. USA 89 (1992) 4957-4961. 
[5] Circolo A., Garnier G., Fukuda W., Wang X., Hidvegi T., Szalai A.J., Briles D.E., Volanakis J.E., Wetsel R.A., Colten H.R., Genetic disruption of the murine complement $C 3$ promoter region generates deficient mice with extrahepatic expression of $C 3$ mRNA, Immunopharmacology 42 (1999) 135-149.

[6] de Bruijn M.H., Fey G.H., Human complement component C3: cDNA coding sequence and derived primary structure, Proc. Natl. Acad. Sci. USA 82 (1985) 708-712.

[7] Fey G.H, Lundwall A., Wetsel R.A., Tack B.F., de Bruijn M.H., Domdey H., Nucleotide sequence of complementary DNA and derived amino acid sequence of murine complement protein C3, Philos. Trans R. Soc. Lond. B. Biol. Sci. 306 (1984) 333-344.

[8] Fong K.Y., Botto M., Walport M.J., So A.K., Genomic organization of human complement component C3, Genomics 7 (1990) 579-586.

[9] Hardge T., Köpke K., Reißmann M., Wimmers K., Maternal influences on litter size and growth in reciprocal crossed miniature pigs and Durocs, Arch. Tierz. Dummerstorf 42 (1999) 83-92.

[10] Kawamura N., Singer L., Wetsel R.A., Colten H.R., Cis- and trans-acting elements required for constitutive and cytokine-regulated expression of the mouse complement C3 gene, Biochem. J. 283 (1992) 705-712.

[11] Komatsu M., Yamamoto K., Nakano Y., Nakazawa M., Ozawa A., Mikami H., Tomita M., Migita S., Hereditary C3 hypocomplementemia in the rabbit, Immunology 64 (1988) 363-368.

[12] Komatsu M., Yoshiwara S., Akita T., Immunological characteristics of the meishan pig: serum complement activity, serum $C 3$ level, immune response and skin structure, in: Proceedings of the 6th World Congress on Genetics Applied to Livestock Production, 11-16 January 1998, Vol. 26, University of New England, Armidale, pp. 323-326.

[13] Kopf M., Abel B., Gallimore A., Carroll M., Bachmann M.F., Complement component $C 3$ promotes T-cell priming and lung migration to control acute influenza virus infection, Nat. Med. 8 (2002) 373-378.

[14] Littell R.C., Henry P.R., Ammerman C.B., Statistical analysis of repeated measures data using SAS ${ }^{\circledR}$ procedures, J. Anim. Sci. 76 (1998) 1216-1231.

[15] Liu C.C., Young J.D., A semiautomated microassay for complement activity, J. Immunol. Methods 114 (1988) 33-39.

[16] Mallard B.A., Wilkie B.N., Kennedy B.W., Influence of major histocompatibility genes on serum hemolytic complement activity in miniature swine, Am. J. Vet. Res. 50 (1989) 359-363.

[17] Misumi Y., Sohda M., Ikehara Y., Nucleotide and deduced amino acid sequence of rat complement C3, Nucleic Acids Res. 25 (1990) 2178.

[18] Ren Y., Liao W.S., Transcription factor AP-2 functions as a repressor that contributes to the liver-specific expression of serum amyloid A1 gene, J. Biol. Chem. 276 (2001) 17770-17778.

[19] Sahu A., Lambris J.D., Structure and biology of complement protein C3, a connecting link between innate and acquired immunity, Immunol. Rev. 180 (2001) 35-48. 
[20] Vaiman M., Hauptmann G., Mayer S., Influence of the major histocompatibility complex in the pig (SLA) on serum haemolytic complement levels, J. Immunogenet. 5 (1978) 59-65.

[21] Vik D.P., Amiguet P., Moffat G.J., Fey M., Amiguet-Barras F., Wetsel R.A., Tack B.F., Structural features of the human $C 3$ gene: intron/exon organization, transcriptional start site, and promoter region sequence, Biochemistry 30 (1991) 1080-1085.

[22] Wessels M.R., Butko P., Ma M., Warren H.B., Lage A.L., Carroll M.C., Studies of group B streptococcal infection in mice deficient in complement component $C 3$ or $C 4$ demonstrate an essential role for complement in both innate and acquired immunity, Proc. Natl. Acad. Sci. USA 92 (1995) 11490-11494.

[23] Wilson D.R., Juan T.S., Wilde M.D., Fey G.H., Darlington G.J., A 58-base-pair region of the human $C 3$ gene confers synergistic inducibility by interleukin-1 and interleukin-6, Mol. Cell Biol. 10 (1990) 6181-6191.

[24] Wimmers K., Lipperheide C., Ponsuksili S., Schmoll F., Hardge T., Petersen B., Schellander K., Haemolytic complement activity and C3c serum concentration in pigs, Arch. Tierz. Dummerstorf 42 (1999) 93-102.

[25] Wimmers K., Mekchay S., Ponsuksili S., Hardge T., Schellander K., Polymorphic sites in exon 15 and 30 of the porcine $C 3$ gene, Anim. Genet. 32 (2001) 46-47.

To access this journal online: www.edpsciences.org 